\title{
Inhibition of hepatocellular carcinoma by fulvestrant involves the estrogen receptor $\alpha$ and Wnt pathways in vitro and in patients
}

\author{
CONG-JUN WANG ${ }^{1 *}$, DE-KAI GUO ${ }^{1}$, TIAN-GENG YOU ${ }^{1 *}$, DONG-WEI SHEN ${ }^{1}$,

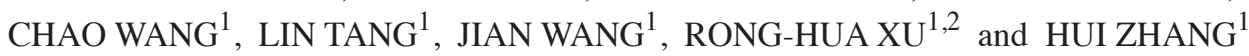 \\ ${ }^{1}$ Department of Hepatobiliary and Pancreatic Diseases, Shanghai East Hospital, Tongji University School of Medicine, \\ Shanghai 200120; ${ }^{2}$ Department of Oncology Surgery, The Affiliated Hospital of Hainan Medical College, \\ Haikou, Hainan 570102, P.R. China
}

Received September 17, 2013; Accepted March 21, 2014

DOI: $10.3892 / \mathrm{mmr} .2014 .2595$

\begin{abstract}
The aim of the present study was to investigate the effect of anti-estrogen treatment (fulvestrant) on the biological activity of hepatocellular carcinoma (HCC), involving the estrogen receptor $\alpha(E R \alpha)$ and Wnt pathways, and to evaluate whether ER $\alpha$ and Wnt inhibitory factor-1 (WIF1) could be biomarkers for anti-estrogen clinical therapy. H22 and HepG2 cells were treated with 0.04 to $625 \mathrm{nM}$ fulvestrant and the WST-8 method was used to assess the inhibition rate after $72 \mathrm{~h}$. Furthermore, prolactin (PRL) secretion by HepG2 cells was assessed at $24 \mathrm{~h}$ using an enzyme immunoassay. Quantitative polymerase chain reaction and western blot analysis were used to analyze the mRNA and protein expression levels of ER $\alpha, \beta$-catenin and WIF1, respectively, in HepG2 cells. For clinical patient analysis, the tumor volume was analyzed by magnetic resonance imaging methods, and PRL in the blood was detected by an enzyme immunoassay. In HepG2 cells, the mRNA and protein expression levels of ER $\alpha$ were downregulated $(\mathrm{P}<0.01)$, while $\beta$-catenin expression remained unchanged and WIF1 expression was upregulated $(\mathrm{P}<0.01)$. Analysis of samples from clinical patients demonstrated that there was a positive correlation between PRL levels and tumor volume. In addition, as compared with non-cancerous tissues, the ER $\alpha$ mRNA levels in tumor tissue were upregulated $(\mathrm{P}<0.05)$, particularly in that of male patients, while WIF1 expression was significantly downregulated $(\mathrm{P}<0.01)$. In conclusion, fulvestrant inhibited the proliferation of HepG2
\end{abstract}

Correspondence to: Dr Rong-Hua Xu or Dr Hui Zhang, Department of Hepatobiliary and Pancreatic Diseases, Shanghai East Hospital, Tongji University School of Medicine, No. 150 Jimo Road, Shanghai 200120, P.R. China

E-mail: xu9.student@126.com

E-mail: zhangh468@sohu.com

*Contributed equally

Key words: estrogen receptor $\alpha$, anti-estrogen, $\beta$-catenin, Wnt inhibitory factor-1, hepatocellular carcinoma cells, involving the ER $\alpha$ and non-canonical Wnt pathways, and it may be a promising therapeutic for HCC.

\section{Introduction}

The fifth most common type of cancer worldwide and the third most common cause of cancer mortality is hepatocellular carcinoma (HCC) (1). HCC was shown to be more prevalent in males compared with females (2). The disease is often diagnosed at a late stage and medical treatments, including chemotherapy, ablation and proton beam therapy are not very effective for these patients. In addition, the majority of patients show disease recurrence and their five-year relative survival rate is only $7 \%$ (3). There is an urgent requirement to develop novel therapies to cure this aggressive disease.

Estrogens have a role in regulating the transcriptional activation of various molecules involved in key cellular processes. These include the generation of immune responses, cell proliferation and apoptosis. Regulation of these processes proceeds through functional receptors, which are located in several sub-cellular organelles (4). Particularly, estrogens have been suggested to act as tumor promoters and induce hepatocarcinogenesis (5). The estrogens exert their effects by binding to estrogen receptors (ERs), including ER $\alpha$ and $\beta$, a subfamily of orphan nuclear receptors closely correlated to the ER (4). ER can actively influence the estrogenic response, indicating that pharmacological modulation of ER activity is likely to be clinically useful to prevent and/or treat a variety of medical conditions (6). However, little is known with regard to the relation of anti-estrogen treatment and ER in HCC.

ER is involved in numerous other pathways, including the mitogen-activated protein kinase and human epidermal growth factor receptor 2 tyrosine kinase pathways and the insulin-like growth factor 1 receptor pathway (7-9). In osteoblastic cells, an interaction between ER and Wnt signaling occurs in order to regulate early gene expression in response to mechanical strain (10). Wnt signaling is an ancient and evolutionary highly conserved system, which has a critical role in regeneration of tissues in adult organisms, embryonic development of all animal species and a number of other processes (11). The Wnt signaling pathway consists of the canonical Wnt/ $\beta$-catenin and non-canonical Wnt inhibitory factor-1 (WIF1) pathway (12). 
However, the role of these pathways in HCC remains to be fully elucidated.

Fulvestrant, a purely anti-estrogenic compound which lacks the estrogen-like activity observed for raloxifene or tamoxifen, has been approved for the treatment of hormone receptor-positive breast cancer in females with disease recurrence following tamoxifen treatment (13). In the present study, H22 and HepG2 cells were treated with different concentrations of fulvestrant. Next, the cell inhibition rate, prolactin (PRL) levels, gene and protein expressions of ER $\alpha$ and two Wnt members, including $\beta$-catenin and WIF1, were analyzed. For clinical patient analysis, the tumor volume and PRL in the blood were tested and mRNA expression levels of ER $\alpha$, $\beta$-catenin and WIF1 in HCC patients' tissues were analyzed.

\section{Materials and methods}

Cell culture and fulvestrant treatment. H22 and HepG2 cell lines were obtained from the Cell Center of the School of Basic Medicine, Shanghai Fudan University (Shanghai, China). The cell lines were cultured in RPMI-1640 medium supplemented with $10 \%$ fetal bovine serum (both from Gibco, Carlsbad, CA, USA), penicillin (100 $\mu \mathrm{g} / \mathrm{ml}$; IndiaMART, Noida, India) and streptomycin $(100 \mu \mathrm{g} / \mathrm{ml}$; IndiaMART, Noida, India), and incubated at $37^{\circ} \mathrm{C}$ in a humidified atmosphere of $5 \% \mathrm{CO}_{2}$. The culture medium was replaced every two days. Prior to drug treatment, the medium was replaced with RPMI-1640 phenol red-free culture medium containing $10 \%$ charcoal-stripped serum (Biological Industries, Beit Haemek, Israel). At $24 \mathrm{~h}$, the cells were treated with different concentrations of fulvestrant (625, 25, 1, 0.04 and $0 \mathrm{nM}$; Sigma, St. Louis, MO, USA) and continued to be cultured for $72 \mathrm{~h}$.

Measurement of cell inhibition rate using the 2-(2-methoxy-4-nitrophenyl)-3-(4-nitrophenyl)-5-(2,4-disulfophenyl)-2H-tetrazolium (WST-8) method. H22 and HepG2 cells in the exponential growth phase were washed two times with phosphate-buffered saline (PBS) and plated in 96-well plates $(5,000$ cells/well) in $100 \mu 1$ phenol red-free RPMI-1640 medium (Mediatech, Inc., Manassas, VA, USA) containing $10 \%$ charcoal-stripped fetal bovine serum. Subsequent to the cell lines being treated with different concentrations of fulvestrant for $72 \mathrm{~h}$, the cell proliferation was assessed with a WST-8 cell staining kit (Neuronbc ${ }^{\mathrm{TM}}$, Beijing, China). Briefly, $10 \mu \mathrm{l}$ of WST-8 solution was added to each well followed by incubation for $4 \mathrm{~h}$. The absorbance at $450 \mathrm{~nm}$ of each well was measured in a SpectraMax ${ }^{\circledR}$ M5 multi-detection microplate reader (Molecular Devices, Sunnyvale, CA, USA). The cell inhibition rate was calculated using the following equation: Inhibition rate $(\%)=($ optical density $(\mathrm{OD})$ of control group - OD of drug group) / OD of control group x 100.

Enzyme immunoassay of PRL secretion. H22 and HepG2 cells were plated into six-well culture plates $\left(\sim 1 \times 10^{4}\right.$ cells/well $)$ and treated with fulvestrant or control medium. In total, $1 \mathrm{ml}$ of medium from each well was collected subsequent to $24 \mathrm{~h}$ treatment prior to staining of the cells and was stored at $-20^{\circ} \mathrm{C}$. The PRL secretion of cells was measured with the rat PRL ELISA kit following the manufacturer's instructions (RapidBio Laboratory, Calabasas, CA, USA). The color intensity of the reaction product (proportional to the concentration of PRL) was measured by the SpectraMax ${ }^{\circledR}$ M5 multi-detection microplate reader. The density of the PRL was calculated by a standard curve. PRL levels in culture medium are a useful indicator of estrogen activity in vitro (14), and PRL secretion of GH3 cells served as an internal control for anti-estrogen activity.

Semi-quantitative polymerase chain reaction ( $q P C R)$ analysis of mRNA expression levels of ER $\alpha, \beta$-catenin and WIF1 in HepG2 cells. Subsequent to a $72 \mathrm{~h}$ treatment, the cells were collected. The total RNA was isolated from the cells using TRIzol reagent (Invitrogen Life Technologies, Carlsbad, CA, USA) and reverse-transcribed into cDNA using $1.5 \mu \mathrm{g}$ of total RNA according to the instructions of the reverse transcription kit supplied by the manufacturer (Tiangen Biotech, Beijing, China). The primers (Invitrogen Life Technologies) used for qPCR are listed in Table I. The qPCR reaction system was performed in a $20 \mu \mathrm{l}$ reaction containing: $2 \mathrm{X}$ Master Mix $(10 \mu \mathrm{l})$, primer $\mathrm{F} / \mathrm{R}(0.5 \mu \mathrm{l}$ each, $10 \mu \mathrm{M})$, sample cDNA $(2 \mu \mathrm{l})$ and $\mathrm{ddH}_{2} \mathrm{O}(7 \mu \mathrm{l})$. The amplification conditions were $95^{\circ} \mathrm{C}$ for $15 \mathrm{sec}, 35$ cycles of $94^{\circ} \mathrm{C}$ for $10 \mathrm{sec}, 60$ or $62^{\circ} \mathrm{C}$ for $20 \mathrm{sec}$ and $72^{\circ} \mathrm{C}$ for $20 \mathrm{sec}$. Reactions were run on a IQ5 real-time PCR detection system (Bio-Rad, Munich, Germany). The relative expression levels of the tested genes were normalized relative to that of the GAPDH (Sigma) and calculated from the cycle threshold value using the $2^{-\Delta \Delta C T}$ method for quantification (15).

Western blot analysis of protein expression levels of ER $\alpha$, $\beta$-catenin and WIF1 in HepG 2 cells. Briefly, the experimental cells were lysed with cell lysis buffer [1\% NP-40, $150 \mathrm{mM}$ $\mathrm{NaCl}, 20$ mM Tris-HCl, 1 mM EDTA, 1 mM ethylene glycol tetraacetic acid and proteinase inhibitor cocktail (1:500; SigmaAldrich)], and their protein concentrations were determined by the Bicinchoninic Acid Protein Assay kit (Pierce, Thermo Scientific, Rockford, IL, USA) prior to separation by gel electrophoresis. Equal amounts of the proteins were subjected to electrophoresis and then transferred onto polyvinylidene fluoride membranes. Following the transfer, the membranes were rinsed and incubated with blocking buffer [5\% skimmed milk in Tris-buffered saline (TBS); Shanghai, China] for 1-2 h at room temperature. The membranes were then incubated overnight with primary antibodies [ER $\alpha$ monoclonal antibody and $\beta$-catenin polyclonal antibody (Abcam, Cambridge, UK); WIF1 polyclonal antibody (Santa Cruz Biotechnology, Santa Cruz, CA, USA)] at $4^{\circ} \mathrm{C}$, followed by three $10 \mathrm{~min}$ washes with Tris-buffered saline, and then incubated with horseradish peroxidase-labeled secondary antibodies (Jackson ImmunoResearch, West Grove, PA, USA) at room temperature for $1 \mathrm{~h}$. Finally, the antibody-antigen complex was detected with an enhanced chemiluminescence detection system (Amersham Pharmacia Biotech, Inc., Piscataway, NJ, USA) using Kodak Biomax XAR film (Kodak, Rochester, NY, USA). The final data were subjected to grayscale scanning and semi-quantitative analysis using the Quantity One software (Bio-Rad, Hercules, CA, USA).

Patients and sample analysis. Blood was collected from patients with HCC preoperatively. Next, PRL levels were assayed by chemiluminescence (Diagnostic Products 
Table I. Primers designed for the human genes the present study's experiment.

\begin{tabular}{|c|c|c|c|c|}
\hline Gene & Size & Forward sequence & Reverse sequence & $\operatorname{Tm}\left({ }^{\circ} \mathrm{C}\right)$ \\
\hline $\operatorname{ER} \alpha$ & 108 & CCACCAACCAGTGCACCATT & GGTCTTTTCGTATCCCACCTTTC & 60 \\
\hline$\beta$-catenin & 116 & AAATAAGCAGGTGGATCTATTTCAT & ACTGGTAAACTGTCCAAAACAAGGT & 62 \\
\hline WIF1 & 92 & GTGTGAAATCAGCAAATGCC & CTCCCTGGTAACCTTTGGAA & 60 \\
\hline GAPDH & 145 & GTCCACTGGCGTCTTCAC & CTTGAGGCTGTTGTCATACTTC & 61 \\
\hline
\end{tabular}

ER $\alpha$, estrogen receptor $\alpha$; WIF1, Wnt inhibitory factor-1; Tm, melting temperature.

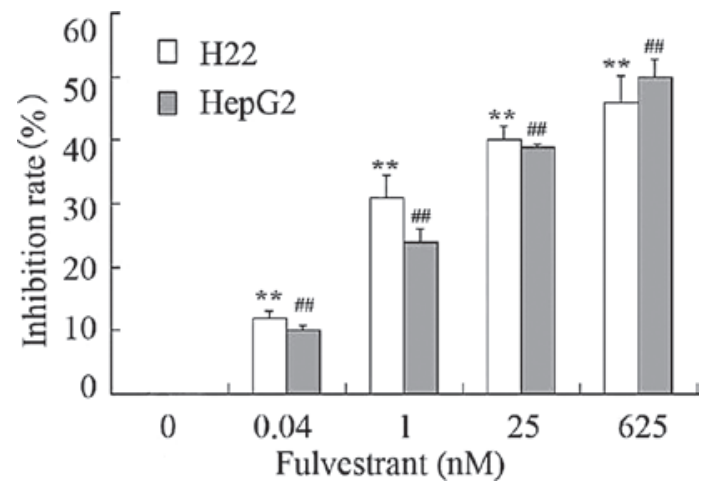

Figure 1. Inhibition of $\mathrm{H} 22$ and HepG2 cell proliferation by fulvestrant. The cells were treated with $0.04,1,25$ and $635 \mathrm{nM}$ fulvestrant for $72 \mathrm{~h}$. The cell viability was determined by WST- 8 staining and expressed as the inhibition rate. The columns show the mean of three samples per group; the bars show the standard deviation. ${ }^{* *} \mathrm{P}<0.01$ in $\mathrm{H} 22$ and ${ }^{\# \#} \mathrm{P}<0.01$ in HepG2 vs. $0 \mathrm{nM}$ group. WST-8, 2-(2-methoxy-4-nitrophenyl)-3-(4-nitrophenyl)-5-(2,4-disulfophenyl)-2H-tetrazolium.

Corporation, Los Angeles, CA, USA) with an Immulite 2000 analyzer (Siemens Medical Solutions Diagnostics, Erlangen, Germany). HCC tissues were obtained from transsphenoidal surgery in the hospital. Each tumor was classified according to the criteria of the 2004 World Health Organization (WHO) classification of endocrine tumors. The tumor volume was analyzed by magnetic resonance imaging (3.0T; General Electric Company, Fairfield, CT, USA) and calculated by the formula: Sagittal $x$ coronal $x$ axial diameters $x \pi / 6$ (16). In the present study, all the HCCs were macroadenomas (diameter $>1 \mathrm{~cm}$ ) since microadenoma specimen are rare. In order to identify possible differences between patients of different gender, the patients were divided into female, male and total patient groups. All the tissues were collected in accordance with the human subjects' approval. The study was approved by the ethics committee of the Department of Hepatobiliary and Pancreatic Diseases, Shanghai East Hospital, Tongji University School of Medicine, Shanghai, China. Written informed consent was obtained from the patient/the patient's family.

The total RNA was extracted from frozen HCC and the normal group (20-50 mg) using TRIzol reagent according to the manufacturer's instructions (Invitrogen Life Technologies). Next, the mRNA expression levels of ER $\alpha, \beta$-catenin and WIF1 were measured according to the procedures mentioned above. The primers for the human genes used for qPCR are listed in Table I.

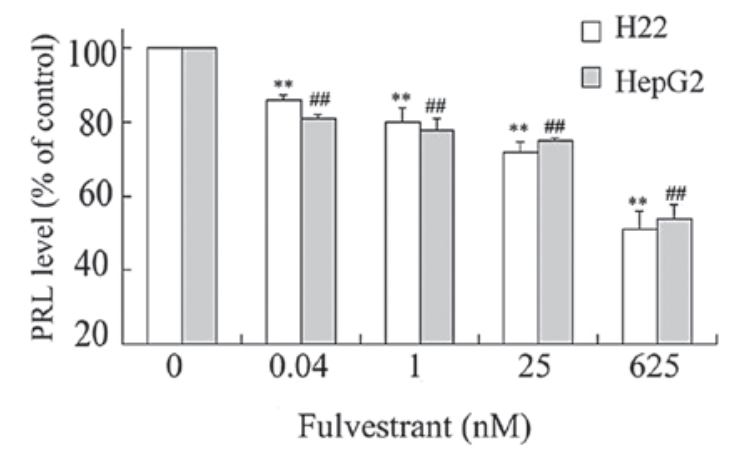

Figure 2. PRL secretion levels following treatment of fulvestrant in $\mathrm{H} 22$ and HepG2 cells. The cells were treated with different concentrations $(0.04,1,25$ and $635 \mathrm{nM}$ ) of fulvestrant for $72 \mathrm{~h}$. The columns are the mean of four samples per group; the bars show the standard deviation.** $\mathrm{P}<0.01$ in $\mathrm{H} 22$ vs. 0 nM group. ${ }^{\# \#} \mathrm{P}<0.01$ in HepG2 vs. 0 nM group. PRL, prolactin.

In an effort to describe the linear association between the tumor volume (Y) and a set of explanatory variables, including the relative ER $\alpha$ levels $\left(\mathrm{X}_{1}\right)$ and gender $\left(\mathrm{X}_{2}\right.$; where female was defined as 0 and male was defined as 1$)$, a multiple linear regression model was developed by a stepwise method.

Statistical analyses. All the data are presented as the mean \pm standard deviation. WST- 8 and ELISA tests were performed four times and repeated three times. All the other tests were performed and repeated three times. A statistical analysis was performed using one-way analysis of variance and the Student's t-test or non-parametric analysis. Correlation or regression analysis was used to determine the correlation between the genes and the clinical characteristics (female was defined as 0 and male was defined as 1 ). $\mathrm{P}<0.05$ and $\mathrm{P}<0.01$ were considered to indicate statistically significant differences between values. SPSS 13.0 for Windows (SPSS Inc., Chicago, IL, USA) was used for statistical analysis.

\section{Results}

Effects of fulvestrant on H22 and HepG2 cell proliferation. H22 and HepG2 cells were treated with 0.04, 1, 25 and $625 \mathrm{nM}$ fulvestrant for $72 \mathrm{~h}$ and the inhibition rate was determined by WST-8 cell staining. As shown in Fig. 1, fulvestrant significantly inhibited the cell growth, and the inhibition rate increased in a dose-dependent manner $(\mathrm{P}<0.01)$. The maximal inhibition rate of the HepG2 cells was $50.28 \pm 3.27 \%$ at a concentration of $625 \mathrm{nM}$, which was the highest tested concentration, and the 
A
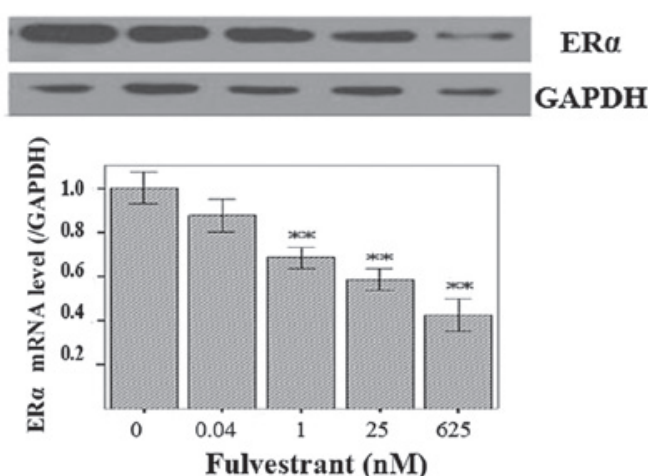
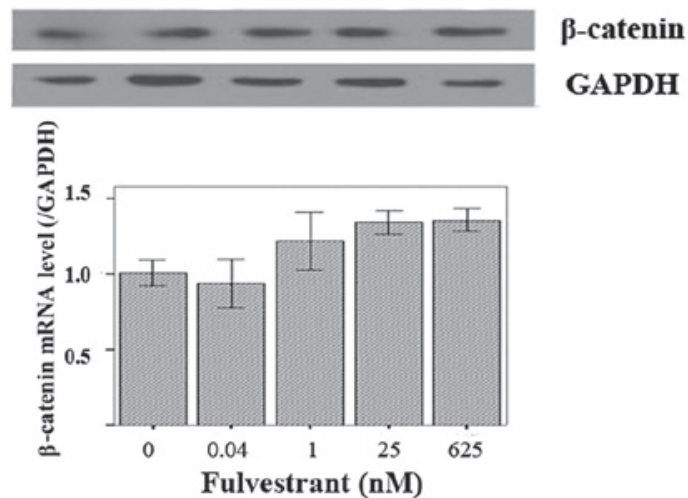

C
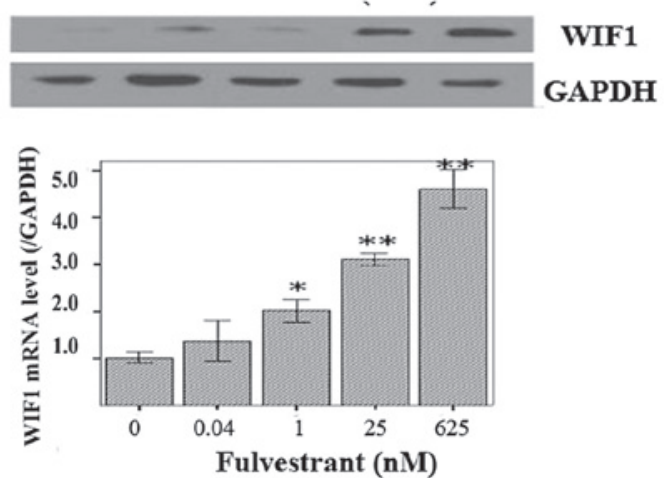

Figure 3. Protein and mRNA expression of (A) ER $\alpha$, (B) $\beta$-catenin and (C) WIF1 in the HepG2 cell line treated with different concentrations (0.04, 1,25 and $635 \mathrm{nM}$ ) of fulvestrant. The columns show the mean of three samples per group; the bars show the standard deviation. ${ }^{*} \mathrm{P}<0.05$ and ${ }^{* * *} \mathrm{P}<0.01 \mathrm{vs} .0 \mathrm{nM}$ group. ER $\alpha$, estrogen receptor $\alpha$; WIF1, Wnt inhibitory factor-1.

A

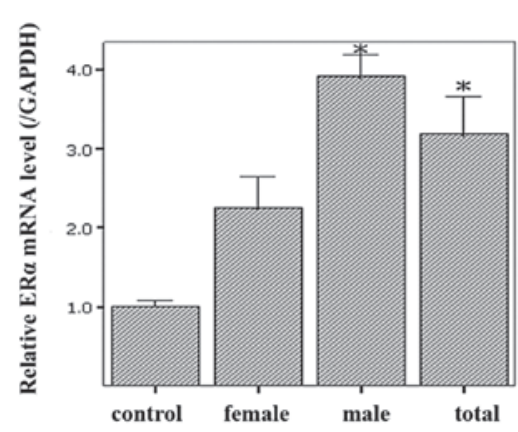

B

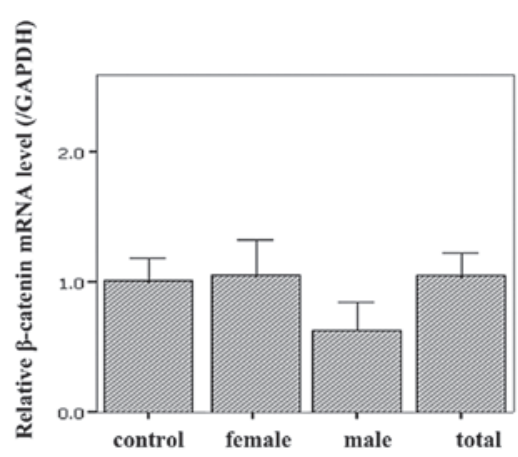

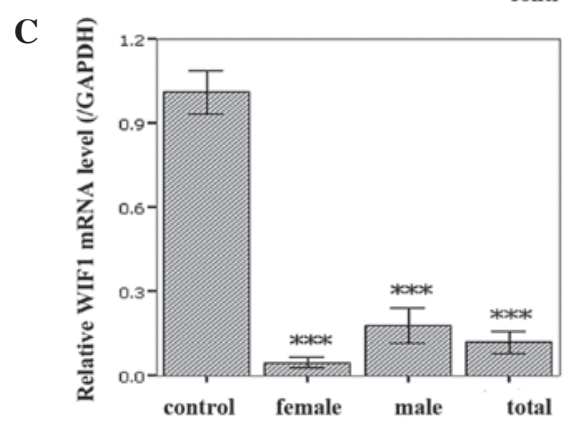

Figure 4. Relative mRNA expression of (A) ER $\alpha$, (B) $\beta$-catenin and (C) WIF1 in clinical patients' tissues. The control group represents non-cancerous tissue. The female group represents hepatocellular carcinoma of female patients. The male group represents hepatocellular carcinoma of male patients. The total group represents tissues from all patients with hepatocellular carcinoma. The columns show the mean of three samples per group; the bars show the standard deviation. ${ }^{*} \mathrm{P}<0.05,{ }^{* *} \mathrm{P}<0.01$ and ${ }^{* * * *} \mathrm{P}<0.001$ vs. control group. ER $\alpha$, estrogen receptor $\alpha$; WIF1, Wnt inhibitory factor-1.

$\mathrm{IC}_{50}$-value of fulvestrant on $\mathrm{H} 22$ and $\mathrm{HepG} 2$ was $478.01 \pm 2.96$ and $298.30 \pm 3.75 \mathrm{nM}$, respectively.
Effects of fulvestrant on PRL secretion. Effects of anti-estrogen treatment on PRL secretion were tested in $\mathrm{H} 22$ and HepG2 cell 
Table II. Semi-quantitative measurement of ER $\alpha, \beta$-catenin and WIF1 protein expression levels by grayscale value.

\begin{tabular}{lccccc}
\hline & \multicolumn{5}{c}{ Fulvestrant concentration (nM) } \\
\cline { 2 - 6 } Protein & 0 & 0.04 & 1 & 25 & 625 \\
\hline ER $\alpha$ & 1 & $0.72 \pm 0.11^{\mathrm{b}}$ & $0.65 \pm 0.09^{\mathrm{b}}$ & $0.61 \pm 0.07^{\mathrm{b}}$ & $0.43 \pm 0.05^{\mathrm{b}}$ \\
$\beta$-catenin & 1 & $0.62 \pm 0.25$ & $1.10 \pm 0.55$ & $1.32 \pm 0.59$ & $0.578 \pm 0.12$ \\
WIF1 & 1 & $0.96 \pm 0.06$ & $1.50 \pm 0.05$ & $1.90 \pm 0.12^{\mathrm{a}}$ & $3.03 \pm 0.93^{\mathrm{b}}$
\end{tabular}

Data are presented as the mean \pm standard deviation. ${ }^{a} \mathrm{P}<0.05$ and ${ }^{\mathrm{b}} \mathrm{P}<0.01$. ER $\alpha$, estrogen receptor $\alpha$; WIF 1 , Wnt inhibitory factor-1.

Table III. Clinical characteristics of hepatocellular carcinoma patients.

\begin{tabular}{lcccc}
\hline Patients (n) & Gender & Age (years) & Prolactin $(\mu \mathrm{g} / 1$, pre-operation) & Tumor size $(\mathrm{mm})$ \\
\hline 202 & M & 37 & 785.8 & $20 \times 30 \times 32$ \\
230 & M & 41 & 329.0 & $14 \times 22 \times 49$ \\
287 & M & 52 & 540.0 & $21 \times 24 \times 32$ \\
211 & F & 56 & 45.81 & $20 \times 22 \times 24$ \\
208 & M & 51 & 290.0 & $16 \times 20 \times 29$ \\
372 & F & 46 & 80.3 & $20 \times 16 \times 13$ \\
375 & M & 29 & 3705 & $37 \times 35 \times 18$ \\
379 & M & 46 & 2899 & $30 \times 30 \times 55$ \\
343 & F & 33 & 108.62 & $20 \times 14 \times 25$ \\
254 & F & 45 & 200.4 & $26 \times 24 \times 16$ \\
214 & F & 24 & & $27 \times 17 \times 10$ \\
\hline
\end{tabular}

F, female; M, male.

Table IV. Parameter estimation of regression model for the correlation between tumor volume, ER $\alpha$ levels and gender.

\begin{tabular}{|c|c|c|c|c|c|}
\hline \multirow[b]{2}{*}{ Model } & \multicolumn{2}{|c|}{ Unstandardized coefficients } & \multicolumn{2}{|c|}{ Standardized coefficients } & \multirow[b]{2}{*}{ P-value } \\
\hline & $\mathrm{B}$ & Standard error & Beta & t-value & \\
\hline (Constant) & -3.036 & 2.637 & & -1.151 & 0.283 \\
\hline $\operatorname{ER} \alpha\left(X_{1}\right)$ & 2.879 & 0.846 & 0.657 & 3.406 & 0.009 \\
\hline Gender $\left(\mathrm{X}_{2}\right)$ & 4.734 & 2.480 & 0.368 & 1.909 & 0.093 \\
\hline
\end{tabular}

ER $\alpha$, estrogen receptor $\alpha$.

lines. The results revealed that fulvestrant decreased the secretion of PRL in H22 and HepG2 cells in a dose-dependent manner (Fig. 2, P<0.01). The maximal suppression rate of PRL secretion levels in HepG2 cells was $53.23 \pm 2.69 \%$ at the concentration of $625 \mathrm{nM}$, which was the highest tested concentration $(\mathrm{P}<0.01)$.

Effects of fulvestrant on the protein and $m R N A$ expression levels of ER $\alpha, \beta$-catenin and WIF1 in the HepG2 cell line. The mRNA expression levels of ER $\alpha$ were significantly downregulated in a dose-dependent manner at fulvestrant concentrations of 1-625 $\mathrm{nM}(\mathrm{P}<0.01$, Fig. $3 \mathrm{~A})$.

The mRNA expression levels of $\beta$-catenin were not significantly affected by the treatment of fulvestrant ( $P>0.05$, Fig. 3B).
The mRNA expression levels of WIF1 increased as the concentration of fulvestrant increased. The mRNA expression levels of WIF1 were significantly upregulated when the concentration was $\geq 1 \mathrm{nM}$. The mRNA levels of WIF1 in the group treated with $625 \mathrm{nM}$ fulvestrant were $\sim$ four times higher compared with those in the control group $(\mathrm{P}<0.01$, Fig. 3C).

Western blot analysis revealed a similar trend to that of the mRNA expression levels (Table II; Fig. 3A and C). The $\mathrm{ER} \alpha$ protein expression was downregulated by fulvestrant in a dose-dependent manner $(\mathrm{P}<0.01)$, while the WIF1 protein expression revealed an ascending trend with increasing concentration of fulvestrant $(\mathrm{P}<0.05)$ and $\beta$-catenin protein 
expression was not markedly changed by different concentrations of fulvestrant.

Correlation between PRL secretion and tumor volume. HCC secrete the hormone PRL (17), which exerts a primary control over the availability of liver ER (18). The clinical characteristics of 11 patients and their PRL levels are presented in Table III. The results revealed that the PRL levels of the male patient group were $\sim 14$ times higher compared with that of the female patient group $(\mathrm{P}<0.01)$ and the tumor volume of the male patient group was $\sim$ three times higher compared to that of the female patient group $(\mathrm{P}<0.05)$. For all the patients, a significant positive association between the PRL level and tumor volume ( $\mathrm{r}=0.778$ and $\mathrm{P}=0.05)$ was identified.

Gene expression of ER $\alpha, \beta$-catenin and WIF1 in tissue of patients. The qPCR results of human specimens are shown in Fig. 4. ER $\alpha$, $\beta$-catenin and WIF1 were detected in all the HCC tissues. ER $\alpha$ mRNA expression levels in the male and the total patient groups were higher compared with the control group $(\mathrm{P}<0.05)$, while there were no statistical differences between the female patient and control groups $(\mathrm{P}=0.16)$ and between the two gender groups $(\mathrm{P}=0.23)$. No significant differences in $\beta$-catenin mRNA expression levels were observed between the four groups $(\mathrm{P}>0.05)$. WIF1 mRNA expression was markedly different between the patient and control groups $(\mathrm{P}<0.001)$, while no significant difference was observed between the two gender groups $(\mathrm{P}=0.11)$.

The main statistics of the final model are demonstrated in Table IV. The results indicated that the response variable $\mathrm{Y}$ was affected by exploratory variables $\mathrm{X}_{1}(\mathrm{P}<0.01)$ and $\mathrm{X}_{2}$. The exploratory variable $\mathrm{X}_{1}$ had the biggest effect on $\mathrm{Y}$ according to the values of standard coefficients.

\section{Discussion}

Fulvestrant is an anti-estrogen drug which causes blockade of residual ER $\alpha$ and ER $\beta$ in breast cells (19). Similarly, Wnt signaling is also a significant pathway involving fulvestrant resistance in breast cells (20). In the present study, it was observed that fulvestrant inhibited proliferation of HCC cell lines and PRL secretion in a dose-dependent manner. The protein and mRNA expression levels of ER $\alpha$ were downregulated, while those of WIF1 were upregulated and $\beta$-catenin remained unchanged. These results indicated that inhibition of HCC-cell proliferation by fulvestrant may proceed via the ER $\alpha$ and Wnt pathways. In the tumor tissue from clinical patients, mRNA expression of ER $\alpha$ was upregulated, while WIF1 was downregulated and $\beta$-catenin remained unchanged.

Overexpression of ER is implicated in the development of $\mathrm{HCC}$ in animal models and humans, and the polymorphisms in the 5' end of the ER $\alpha$ gene have been revealed to be associated with an increased HCC risk, supporting the hypothesis of involvement for the estrogen-ER axis in the estrogen-induced hepatocarcinogenesis (21). In the present study, mRNA and protein expression of $\mathrm{ER} \alpha$ decreased when the concentration was $\geq 1 \mathrm{nM}$. Therefore, fulvestrant may be a promising therapeutic for HCC treatment.

The molecular mechanisms of estrogen action in HCC are complex and Wnt also has a significant role in $\mathrm{HCC}$ regulation of cell growth and survival (22). However, whether fulvestrant acts via the Wnt pathway in HepG2 cells besides the ER $\alpha$ pathway had yet to be elucidated. The present study focused on total $\beta$-catenin and identified that the expression of $\beta$-catenin was not changed significantly when HepG2 cells were treated with fulvestrant. Thus, the $\mathrm{Wnt} / \beta$-catenin pathway may not be significant in HCC, but rather through the other non-canonical pathways.

One of the key genes in the Wnt signal transduction pathway is WIF1; WIF1's subnormal function can contribute to the activation of the Wnt pathway, cell proliferation and differentiation are dysregulated, and as a result, carcinogenesis occurs (23). In the present study, WIF1 was upregulated following treatment with fulvestrant in a dose-dependent manner in HCC cell lines. The results indicated that fulvestrant exerted its effect through non-canonical Wnt pathways in HCC. A previous study demonstrated that overexpression of ER $\alpha$ in breast cancer cells increased the mRNA expression of WIF-1 (24). These results appeared to differ from those of the present study, in which $\mathrm{ER} \alpha$ was downregulated and WIF1 was upregulated following fulvestrant treatment. However, the detailed correlation of ER and WIF1 remain to be fully elucidated in HCC and further experiments are required.

An analysis of tissue from clinical patients demonstrated that there was a positive correlation between the PRL levels and tumor volume. Similar phenomena are reported stating that tumor size was correlated with serum PRL (25). The ER $\alpha$ mRNA expression levels were upregulated in HCC tissues compared with those in non-cancerous tissues. Ohnishi et al (26) also demonstrated that ER is expressed twice as much in HCC than in surrounding noncancerous tissues. In addition, a linear regression analysis revealed that there was a linear association between $\mathrm{ER} \alpha$, gender and tumor volume. $\beta$-catenin mRNA expression remained unchanged in HCC tissues compared with non-cancerous tissues. However, WIF1 mRNA expression was downregulated in HCC compared with that in non-cancerous tissues. Deng et al (27) revealed that there was significantly low expression of WIF1 mRNA in HCC clinical samples. The expression of ER $\alpha, \beta$-catenin and WIF1 coincided with that in HepG2 cells. The treatment of fulvestrant inhibited proliferation by downregulating ER $\alpha$ and upregulating WIF1.

In conclusion, anti-estrogen treatment inhibited proliferation and PRL secretion in H22 and HepG2 cells via the ER $\alpha$ and non-canonical Wnt/WIF1 pathways. Furthermore, analysis of tissues from clinical patients revealed a positive correlation between the PRL levels and tumor volume, and there was also a linear correlation between the $\mathrm{ER} \alpha$ and tumor volume. These observations indicated that anti-estrogen treatment using fulvestrant may be a promising medical strategy for HCC treatment, and ER $\alpha$ and WIF1 may be used as potential biomarkers of fulvestrant activity for HCC clinical trials and/or with the rationale to be combined with other chemotherapeutic agents.

\section{Acknowledgements}

This study was supported by grants from the National Natural Science Foundation of China (nos. 30872510, 81272534 and 81260349), the Natural Science Foundation of Hubei Province (nos. 2008CDB127), and the Natural Science Foundation of Shanghai (nos. 064119620 and 10411968400). 


\section{References}

1. El-Serag HB and Rudolph KL: Hepatocellular carcinoma: epidemiology and molecular carcinogenesis. Gastroenterology 132: 2557-2576, 2007.

2. El-Serag HB: Hepatocellular carcinoma: recent trends in the United States. Gastroenterology 127: S27-S34, 2004.

3. Bosch FX, Ribes J, Díaz M and Cléries R: Primary liver cancer: worldwide incidence and trends. Gastroenterology 127: S5-S16, 2004.

4. Boonyaratanakornkit V and Edwards DP: Receptor mechanisms mediating non-genomic actions of sex steroids. Semin Reprod Med 25: 139-153, 2007.

5. CoeJE,Ishak KG and Ross MJ: Estrogen induction of hepatocellular carcinomas in Armenian hamsters. Hepatology 11: 570-577, 1990.

6. Giguère V: To ERR in the estrogen pathway. Trends Endocrino Metab 13: 220-225, 2002.

7. Bunone G, Briand PA, Miksicek R and Picard D: Activation of the unliganded estrogen receptor by EGF involves the MAP kinase pathway and direct phosphorylation. EMBO J 15: 2174-2183, 1996.

8. Pietras RJ, Arboleda J, Reese DM, et al: HER-2 tyrosine kinase pathway targets estrogen receptor and promotes hormone-independent growth in human breast cancer cells. Oncogene 10: 2435-2446, 1995.

9. Kahlert S, Nuedling S, van Eickels M, Vetter H, Meyer R and Grohe C: Estrogen receptor alpha rapidly activates the IGF-1 receptor pathway. J Biol Chem 275: 18447-18453, 2000.

10. Liedert A, Wagner L, Seefried L, Ebert R, Jakob F and Ignatius A: Estrogen receptor and Wnt signaling interact to regulate early gene expression in response to mechanical strain in osteoblastic cells. Biochem Biophys Res Commun 394: 755-759, 2010.

11. Klaus A and Birchmeier W: Wnt signalling and its impact on development and cancer. Nat Rev Cancer 8: 387-398, 2008

12. Grumolato L, Liu G, Mong P, et al: Canonical and noncanonical Wnts use a common mechanism to activate completely unrelated coreceptors. Genes Dev 24: 2517-2530, 2010.

13. Ingle JN, Suman VJ, Rowland KM, et al: Fulvestrant in women with advanced breast cancer after progression on prior aromatase inhibitor therapy: North Central Cancer Treatment Group Trial N0032. J Clin Oncol 24: 1052-1056, 2006.

14. Dang VH, Nguyen TH, Lee GS, Choi KC and Jeung EB: In vitro exposure to xenoestrogens induces growth hormone transcription and release via estrogen receptor-dependent pathways in rat pituitary GH3 cells. Steroids 74: 707-714, 2009.
15. Livak KJ and Schmittgen TD: Analysis of relative gene expression data using real-time quantitative PCR and the 2[-Delta Delta C(T)]. Method 25: 402-408, 2001.

16. Carlsson G, Gullberg B and Hafström L: Estimation of liver tumor volume using different formulas - an experimental study in rats. J Cancer Res Clin Oncol 105: 20-23, 1983.

17. Boutin JM, Edery M, Shirota M, et al: Identification of a cDNA encoding a long form of prolactin receptor in human hepatoma and breast cancer cells. Mol Endocrinol 3: 1455-1461, 1989.

18. Chamness GC, Costlow ME and McGuire WL: Estrogen receptor in rat liver and its dependence on prolactin. Steroids 26: 363-371, 1975.

19. Yue W, Wang JP, Li Y, et al: Effects of estrogen on breast cancer development: Role of estrogen receptor independent mechanisms. Int J Cancer 127: 1748-1757, 2010.

20. Fan M, Yan PS, Hartman-Frey C, et al: Diverse gene expression and DNA methylation profiles correlate with differential adaptation of breast cancer cells to the antiestrogens tamoxifen and fulvestrant. Cancer Res 66: 11954-11966, 2006.

21. Zhai Y, Zhou G, Deng G, et al: Estrogen receptor alpha polymorphisms associated with susceptibility to hepatocellular carcinoma in hepatitis B virus carriers. Gastroenterology 130: 2001-2009, 2006

22. Polakis P: Wnt signaling and cancer. Genes Dev 14: 1837-1851, 2000.

23. Ding Z, Qian YB, Zhu LX and Xiong QR: Promoter methylation and mRNA expression of DKK-3 and WIF-1 in hepatocellular carcinoma. World J Gastroenterol 15: 2595-2601, 2009.

24. Wu D, Wong P, Li W, Vogel CF and Matsumura F: Suppression of WIF-1 through promoter hypermethylation causes accelerated proliferation of the aryl hydrocarbon receptor (AHR) overexpressing MCF10AT1 breast cancer cells. Toxicology 285: 97-103, 2011.

25. van der Lely AJ, Harris AG and Lamberts S: The sensitivity of growth hormone secretion to medical treatment in acromegalic patients: influence of age and sex. Clin Endocrinol (Oxf) 37: 181-185, 1992.

26. Ohnishi S, Murakami T, Moriyama T, Mitamura K and Imawari M: Androgen and estrogen receptors in hepatocellular carcinoma and in the surrounding noncancerous liver tissue. Hepatology 6: 440-443, 1986.

27. Deng Y, Yu B, Cheng Q, et al: Epigenetic silencing of WIF-1 in hepatocellular carcinomas. J Cancer Res Clin Oncol 136: 1161-1167, 2010. 